\title{
Effect of Link Dimensions on D Type Eccentric Steel Frames
}

\author{
Mazen Ali Musmar \\ Department of Civil Engineering, Faculty of Engineering, \\ Al-Ahliyya Amman University, Amman, Jordan
}

Received 2012-09-20, Revised 2013-03-01; Accepted 2013-02-12

\begin{abstract}
In seismic prone regions, buildings are designed to maintain sufficient stiffness during moderate earthquakes and to absorb and dissipate a large amount of the energy released due to severe earthquakes. The usual steel framing systems; the moment frames require larger member sections to satisfy stiffness requirements and have large ductility capacity, the concentrically braced frames satisfy stiffness on the expense of ductility requirements, resulting in poor energy dissipation. This study deals with the eccentrically Braced Steel Frames (EBF). EBF configuration is similar to traditional braced frames with the exception that at least one end of each brace must be eccentrically connected to the frame. The energy dissipation is achieved through the yielding of a beam segment called the link, while the other frame members, including outer beam segments, braces and columns, should remain essentially elastic. EBFs offer an economical steel framing system satisfying both stiffness and ductility requirements. The study incorporates conducting nonlinear finite element analysis to study the effect of the link length and link section on the behavior of D types EBF systems. The study involves material and geometric nonlinearities.
\end{abstract}

Keywords: D-Type Eccentric Frames, Nonlinear Analysis, Steel Frames

\section{INTRODUCTION}

Moment Resisting Frames (MRFs) are very common in the construction of single story steel buildings. The MRF has large ductility capacity as compared to other frame types, but the ductility demand on this frame is highly sensitive to the gravity loads that act on its members (Park et al., 1997), thus MRF requires larger member sizes to keep lateral deflections with the code mandated limits compared to other frames systems (Bruneau et al., 2011).

Roeder and Popov (1978) suggested the Eccentrically Braced Frame (EBF) system in which a distance is either created between the two ends of the bracing members, or between the bracing member and the column, or between the bracing member and the beam as shown in Fig 1. The created distance is called link (e). The main function of the link is to provide a weak section in the frame which provides plastic deformation capacity and dissipate the energy released by the earthquake.
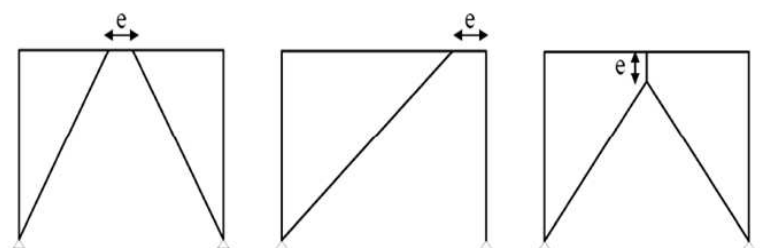

Fig. 1. Link in eccentrically braced frame

Concentrically Braced Frames (CBFs) possess high elastic stiffness which result in hampering large drifts and its ability to dissipate energy solely depends on the unstable hysteretic behavior of the braces that may result in loss of lateral stiffness and strength of the frame due to the effect of buckling (Black et al., 1980). According to (Mitsumasa et al., 1996), the building response to a severe earthquake motion can be controlled by increasing the dissipation energy caused by plastic deformations of energy dissipation members built into a frame structure. 


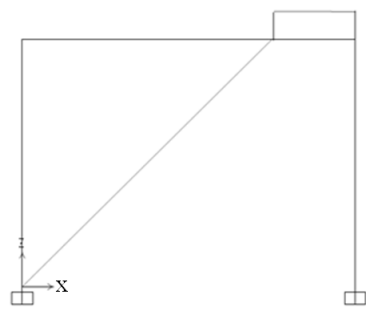

(a)

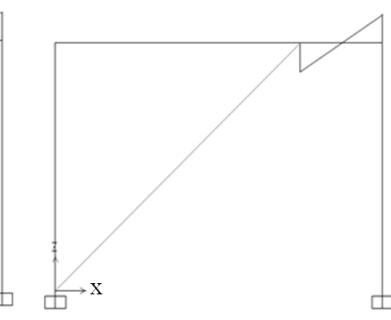

(b)
Fig. 2. Internal forces along the link in a D-type EBF, (a) shear force diagram, (b) bending moment diagram

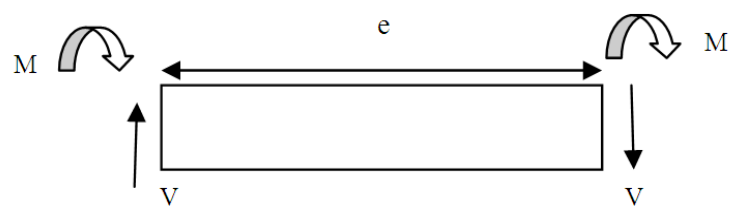

Fig. 3. Internal forces acting on the link

Lee and Bruneau (2005) reported that shear yielding in CBFs allow for the development of large plastic deformations without the development of excessive local strains that occur in flexural yielding. Kasai and Popov (1986) stated that shear yielding provides a larger energy dissipation capacity than flexural yielding.

Figure 2a indicates that the shear force is constant along the whole link length, while Fig. 2b shows that large bending moments occur only at the ends and that it is a reverse curvature bending.

As illustrated in Fig. 2 and 3, end moments are close in values and may be approximated as equal. Thus equilibrium of internal forces along the link member yields:

$$
\mathrm{e}=\frac{2 \mathrm{M}}{\mathrm{v}}
$$

where, $2 \mathrm{M}$ represents the sum of the internal clockwise end moments, acting on the two ends of the link under double curvature bending. Due to strain hardening in plastic stage, shear link can bear $1.5 \mathrm{Vp}$ and $1.2 \mathrm{Mp}$, where $\mathrm{Vp}$ and $\mathrm{Mp}$ are the plastic shear and the plastic moment of the link respectively. Substituting in Equation 1 and 2, the plastic shear dominates in the link as long as:

$$
\begin{aligned}
& \mathrm{e} \leq \frac{2 \mathrm{M}}{\mathrm{V}} ; \mathrm{e} \leq \frac{2 \times 1.2 \mathrm{M}_{\mathrm{p}}}{1.5 \mathrm{~V}_{\mathrm{P}}} \\
& \text { resulting in } \quad \mathrm{e} \leq \frac{1.6 \mathrm{M}_{\mathrm{p}}}{\mathrm{V}_{\mathrm{P}}}
\end{aligned}
$$

This is in accordance with AISC (2006), where links are categorized as:

- Short links, shear links, $\mathrm{e} \leq \frac{1.6 \mathrm{M}_{\mathrm{p}}}{\mathrm{V}_{\mathrm{p}}}$

- Long links, flexural links, e $>\frac{2.6 \mathrm{M}_{\mathrm{p}}}{\mathrm{V}_{\mathrm{p}}}$

- Intermediate links, $\frac{1.6 \mathrm{M}_{\mathrm{p}}}{\mathrm{V}_{\mathrm{p}}}<\mathrm{e}<\frac{2.6 \mathrm{M}_{\mathrm{P}}}{\mathrm{V}_{\mathrm{p}}}$

Where:

$\mathrm{M}_{\mathrm{p}}=$ Nominal plastic moment capacity, N.mm

$\mathrm{V}_{\mathrm{p}}=$ Nominal plastic shear capacity, $\mathrm{N}$

$\mathrm{E}=$ Link length, $\mathrm{mm}$

The objective of this study is to study the effect of the link length and link section on the behavior of D-type eccentric bay frames. The study involves material and geometric nonlinearities.

\section{FINITE ELEMENT ANALYSIS}

ANSYS finite element software is used. Eight single story D-type eccentric bay frames are modeled in addition to a concentrically braced frame. As listed in Table 1 the link length is variable, also two different link sections are adopted, one similar to that of the adjacent beam section and is referred to as the normal section and the other is a reduced section and is referred to as the reduced section. The bracing is so proportioned so as not to buckle at the ultimate strength of the frame.

The frame height is $3 \mathrm{~m}$, the bay length is $4 \mathrm{~m}$ and all input parameters are listed in Table 1. Link is so proportioned that during plastic deformation the web yields before the plastic moment capacity is reached at the link ends. The required shear strength values given in Table 2 are calculated in Accordance with AISC (2006) provisions:

$$
\mathrm{Vu} \leq \varnothing_{\mathrm{v}} \mathrm{V}_{\mathrm{n}}
$$

$\mathrm{V}_{\mathrm{n}}=$ The nominal shear strength of the link and is equal to the lesser of $\mathrm{V}_{\mathrm{p}}$ and $2 \mathrm{Mp} / \mathrm{e}$

$\mathrm{e}=$ Link length

$\mathrm{Vp}=0.6 \mathrm{~F}_{\mathrm{y}} \mathrm{A}_{\mathrm{w}} ; \mathrm{A}_{\mathrm{w}}=\mathrm{d}^{*} \mathrm{t}_{\mathrm{w}}$

$\varnothing_{\mathrm{v}}=1$

\section{MODELING}

The physical properties of the steel sections are listed in Table 1. The link sections and lengths and the required shear strength values are given in Table 2. 
Table 1. Properties of the steel sections

\begin{tabular}{ll}
\hline Material Model prior to yield surface & Linear elastic \\
\hline Elastic modulus & $200 \mathrm{GPa}$ \\
Poisson's ratio & 0.3 \\
Yield stress, fy & $250 \mathrm{MPa}$ \\
Tangent modulus beyond yield surface & $2 \mathrm{GPa}$ \\
\hline
\end{tabular}

Table 2. The parametric dimensions of the model

\begin{tabular}{lllrlr}
\hline & Link type & $\mathrm{e}(\mathrm{mm})$ & $2 \mathrm{M}_{\mathrm{p}} / \mathrm{e}$ & $\mathrm{V}_{\mathrm{p}}(\mathrm{KN})$ & $\phi \mathrm{Vn}(\mathrm{KN})$ \\
\hline 1 & $\mathrm{~W} 16 \times 36$ & 200 & 2050 & 485 & 514 \\
$1 \mathrm{~b}$ & $\mathrm{~W} 10 \times 19$ & & 434 & 228 & 247 \\
2 & $\mathrm{~W} 16 \times 36$ & \multirow{2}{*}{300} & 1370 & 485 & 514 \\
$2 \mathrm{~b}$ & $\mathrm{~W} 10 \times 19$ & & 290 & 228 & 247 \\
3 & $\mathrm{~W} 16 \times 36$ & \multirow{2}{*}{400} & 1030 & 485 & 514 \\
$3 \mathrm{~b}$ & $\mathrm{~W} 10 \times 19$ & & 217 & 228 & 217 \\
4 & $\mathrm{~W} 16 \times 36$ & 500 & 822 & 485 & 514 \\
$4 \mathrm{~b}$ & $\mathrm{~W} 10 \times 19$ & & 174 & 228 & 174 \\
\hline
\end{tabular}

Columns section: W16 $\times 36$, Beam section: W16 $\times 36$, Bracing: HSS $8 \times 8 \times 1 / 2$

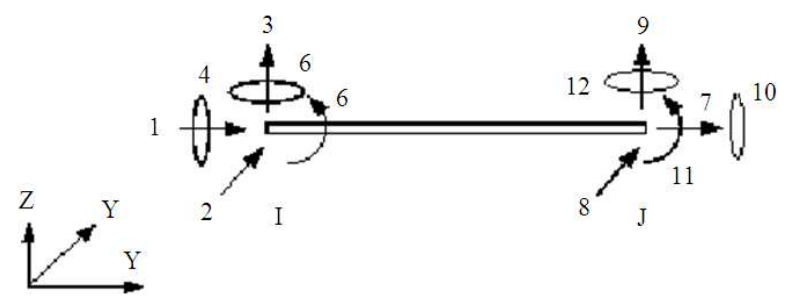

Fig. 4. Beam189 element

Figure 4 illustrate Beam189 element that is used to model all members of the eccentric frame. It is a quadratic beam element, it is well-suited for linear, large rotation and/or large strain nonlinear applications, elasticity, creep and plasticity models are supported.

Six degrees of freedom exist at each node, these include translations in the $\mathrm{x}, \mathrm{y}$ and $\mathrm{z}$ directions and rotations about the $\mathrm{x}, \mathrm{y}$ and $\mathrm{z}$ directions, the plasticity model is based on Von Mises yielding criteria and it is associated flow rule (ANSYS, 1998).

\section{LOADING AND BOUNDARY CONDITIONS}

Primarily Eigen value buckling analysis was used to determine the theoretical buckling load. Such analysis assumes that the structure exhibits linearly elastic behavior, thus the predicted buckling load is overestimated. Based on the predicted load, Nonlinear buckling analysis was carried out. The applied horizontal load was gradually increased, employing non-linear, large-deflection, until a load level was found whereby the structure became unstable. The column supports were assumed to be fixed. The recorded value of lateral displacement was at the beam column joint.

\section{DISCUSSION}

The study was conducted using eight single story Dtype eccentric bay frames having dimensions as listed in Table 2 and geometry as shown in Fig. 5a, 6a.

In frames 1,2,3,4 normal link sections of lengths that varied from $200 \mathrm{~mm}$ to $500 \mathrm{~mm}$, with $100 \mathrm{~mm}$ increments, are used. In frames $1 b, 2 b, 3 b, 4 b$ reduced link sections with lengths that varied from $200 \mathrm{~mm}$ to 500 $\mathrm{mm}$ are utilized. A ninth D-type braced frame with no shear link, or having e $=0.0$, is also analyzed to compare the load deflection obtained results.

Figure 5b shows that in the case of the normal link section of $500 \mathrm{~mm}$ length, the lateral drift at the first yield load is $7.13 \mathrm{~mm}$ and that the lateral drift becomes $18.2 \mathrm{~mm}$ just before inelastic buckling load.

Figure $6 \mathbf{b}$ shows that that in the case of reduced link section of $500 \mathrm{~mm}$ length, the lateral drift at the first yield mounts up to $7.4 \mathrm{~mm}$, the lateral drift just before inelastic buckling load becomes $58.2 \mathrm{~mm}$, implying that more ductility is attained.

Also Fig. 5b shows that in the case of normal link section of $500 \mathrm{~mm}$ length, the first yield load is $875 \mathrm{KN}$, which is about $70 \%$ of the inelastic buckling load of $1250 \mathrm{KN}$. Figure $\mathbf{6 b}$ indicates that in the case of reduced section link, the obtained first yield load value is $575 \mathrm{KN}$, which is about $46 \%$ of the inelastic buckling load. The degradation in stiffness in the case of the reduced section link compared to that of the same length normal section link is attributed to the initiation of shear inelastic deformation within the shear link at a lower load step, indicating that inelastic deformations and energy dissipation occur earlier and at a lower load value, resulting in better ductility when using link of reduced section.

Figure 5d and 6d indicate that in both cases using normal and reduced link sections, the link is subjected to the highest internal shear forces among all frame members. Figure 5c shows that maximum bending moments occur at the link ends.

Figure 5e, 5f and 6c, 6e, 6f illustrate Von Mises stresses for the frame with $500 \mathrm{~mm}$ link long sections at a load step close to the inelastic buckling load. At this load step, the link internal Von Mises stresses exceed the steel yield stress, while stresses for all other frame members are still below the yield stress. Comparing the values of Von Mises stresses and the amount of inelastic deformation in both normal and reduced sections, it can be concluded that reducing the link section in the D-type Eccentric frame enhances ductility and the ability to dissipate energy, while maintaining tangible stiffness and stability of the frame at severe loadings. 


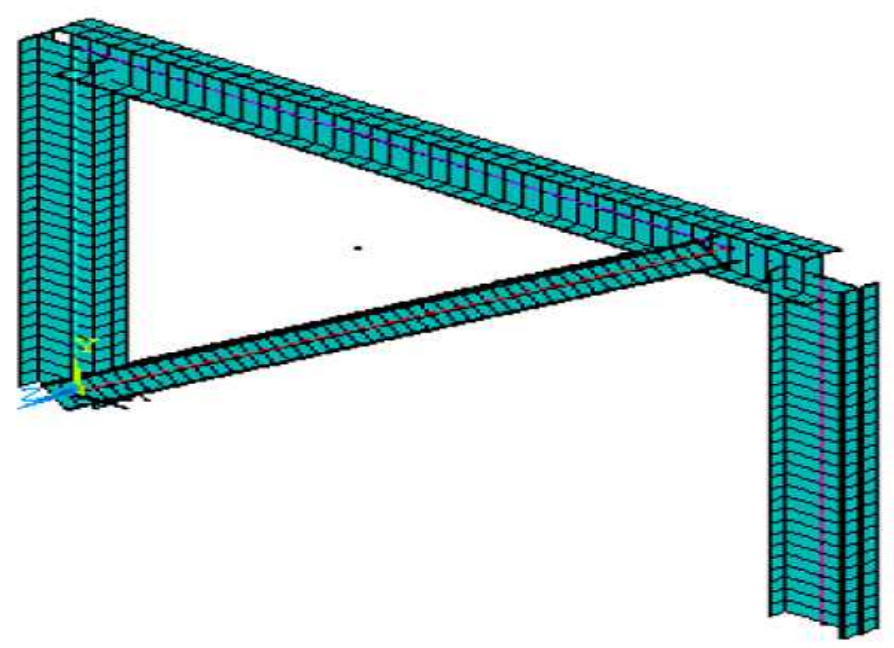

(a)

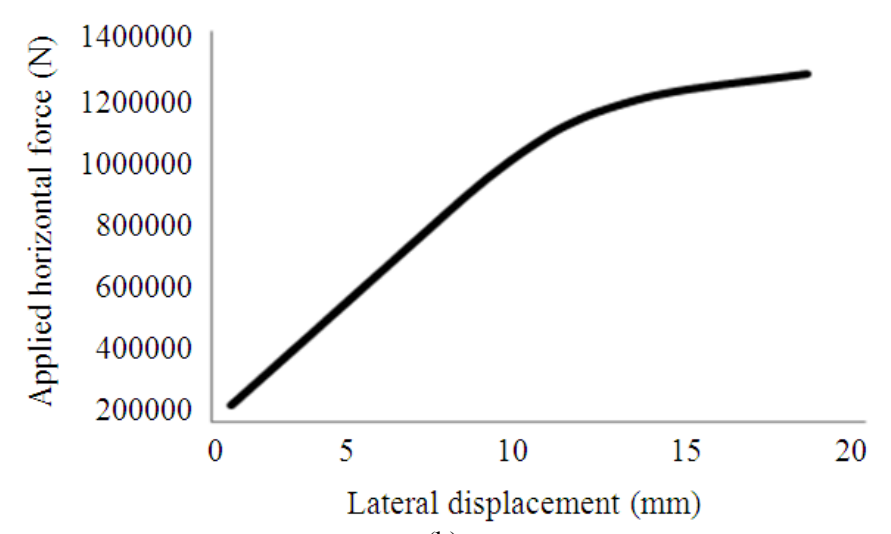

(b)

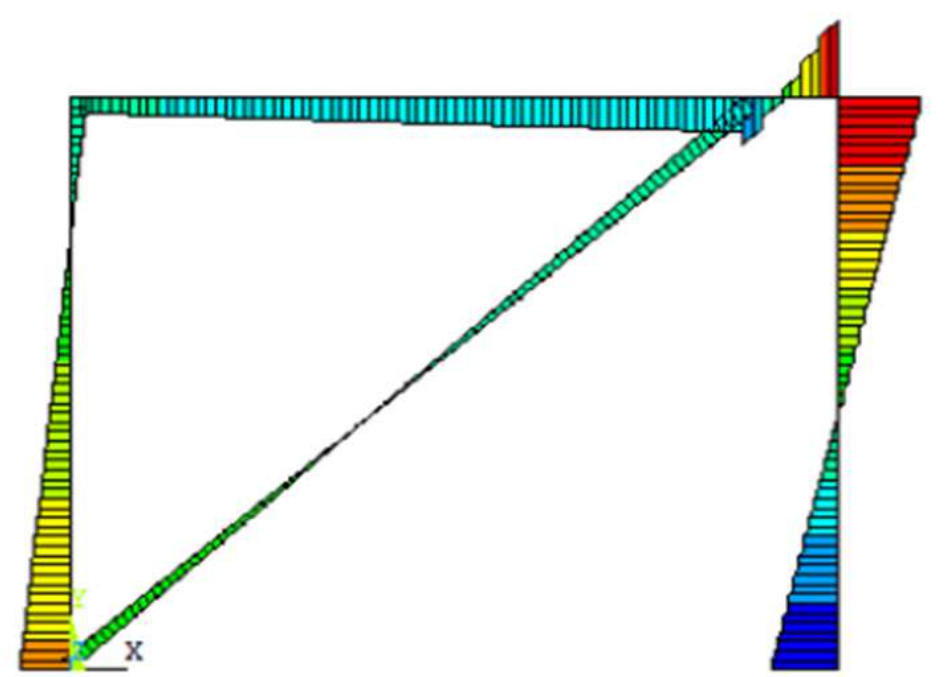

(c) 
Mazen Ali Musmar / American Journal of Engineering and Applied Sciences 6 (1): 31-41, 2013

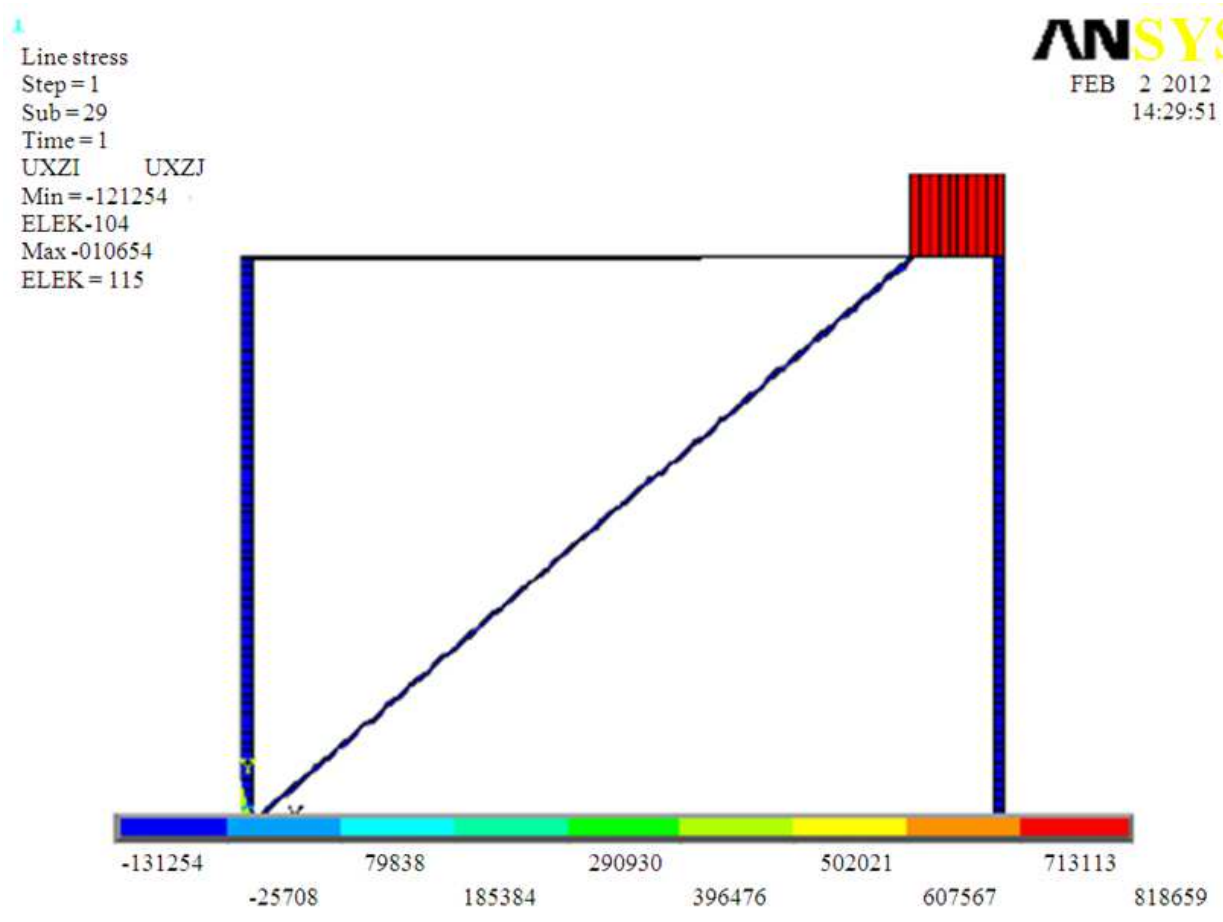

D_type_braced_nonlinear

(d)

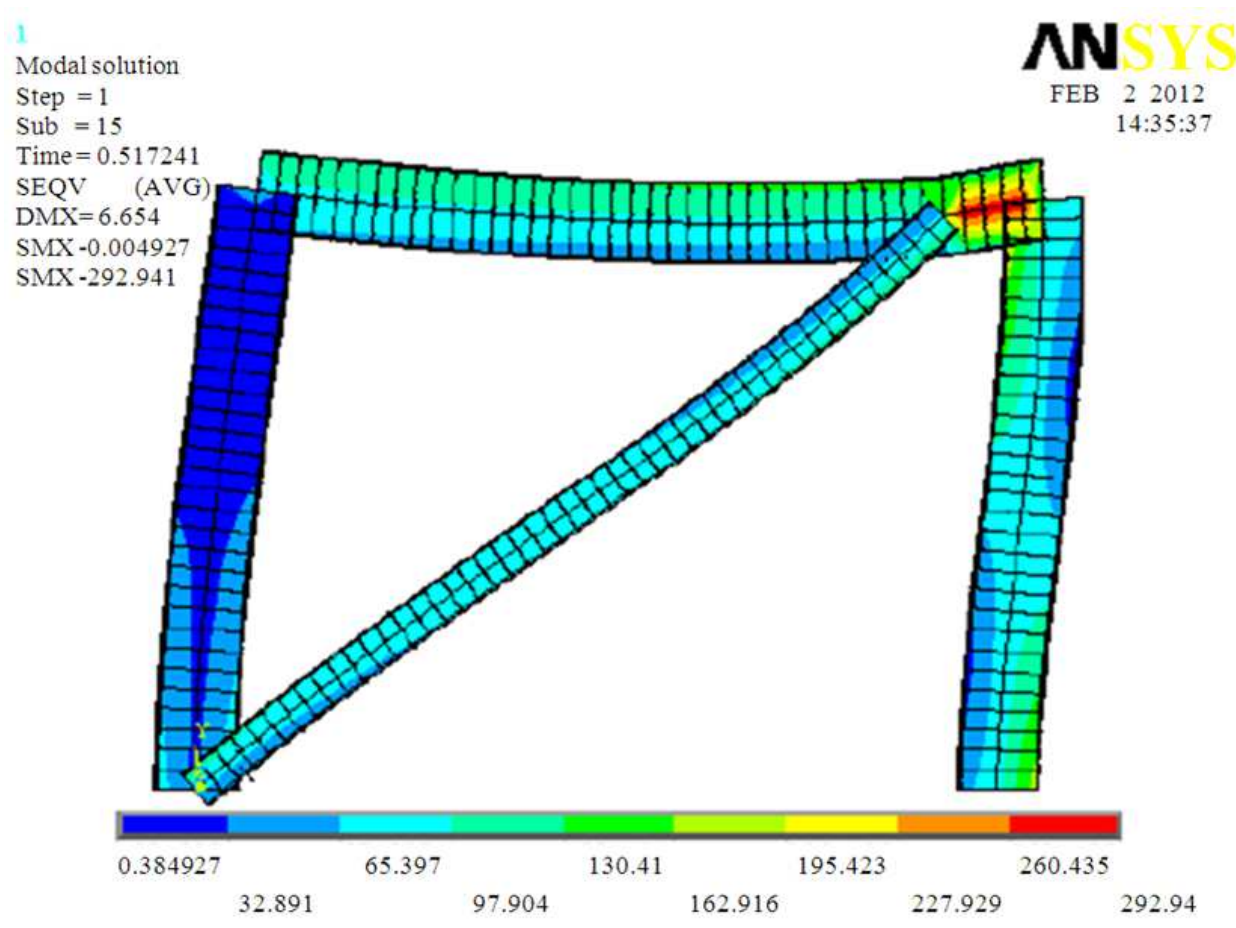

D_type_braced_nonlinear

(e) 
Mazen Ali Musmar / American Journal of Engineering and Applied Sciences 6 (1): 31-41, 2013

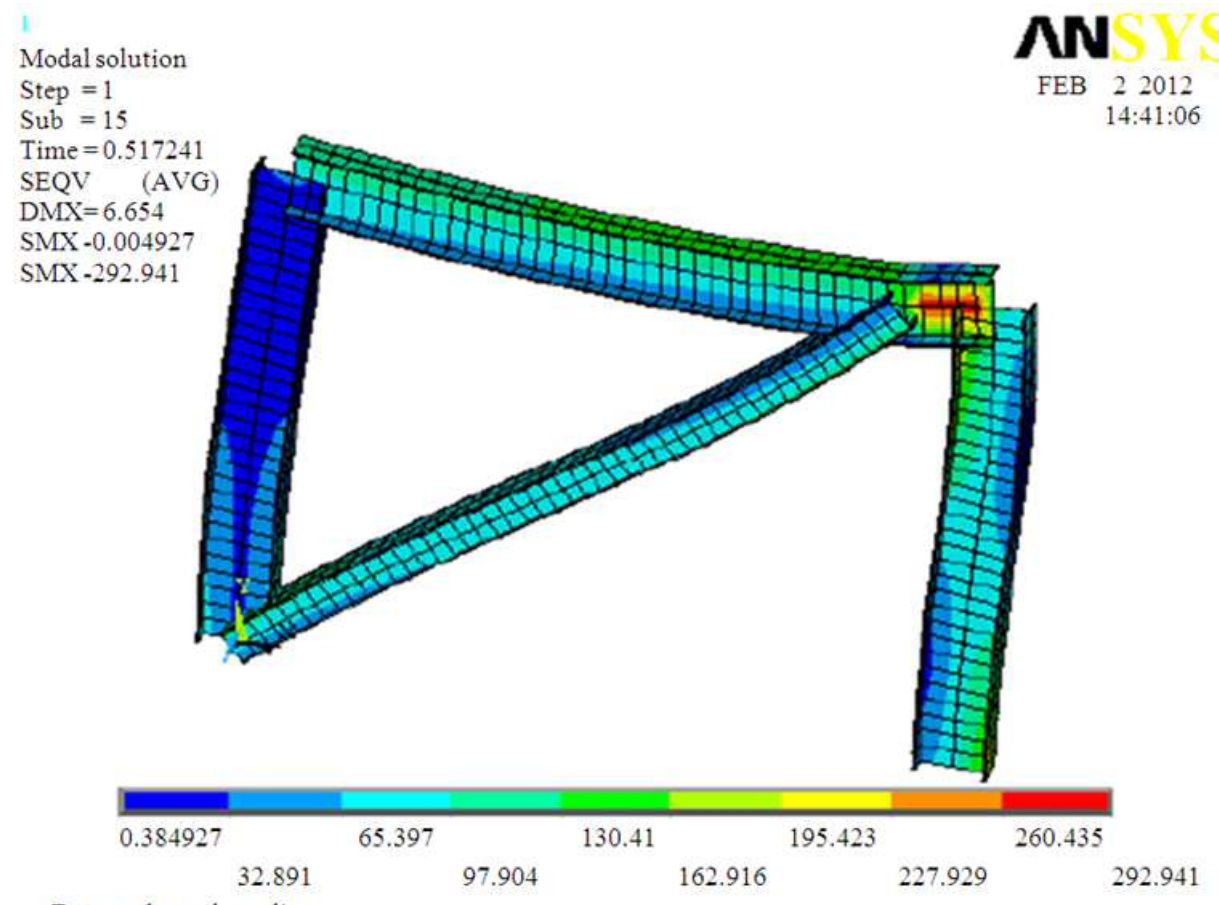

D_type_braced_nonlinear

(f)

Fig. 5. (a) Isometric view of D-braced frame, (b) Load def-lection curve, (c) Bending Moment diagram, (d) Shear Force diagram, (e) Von Mises stresses, (f) Von Mises stresses isometric view

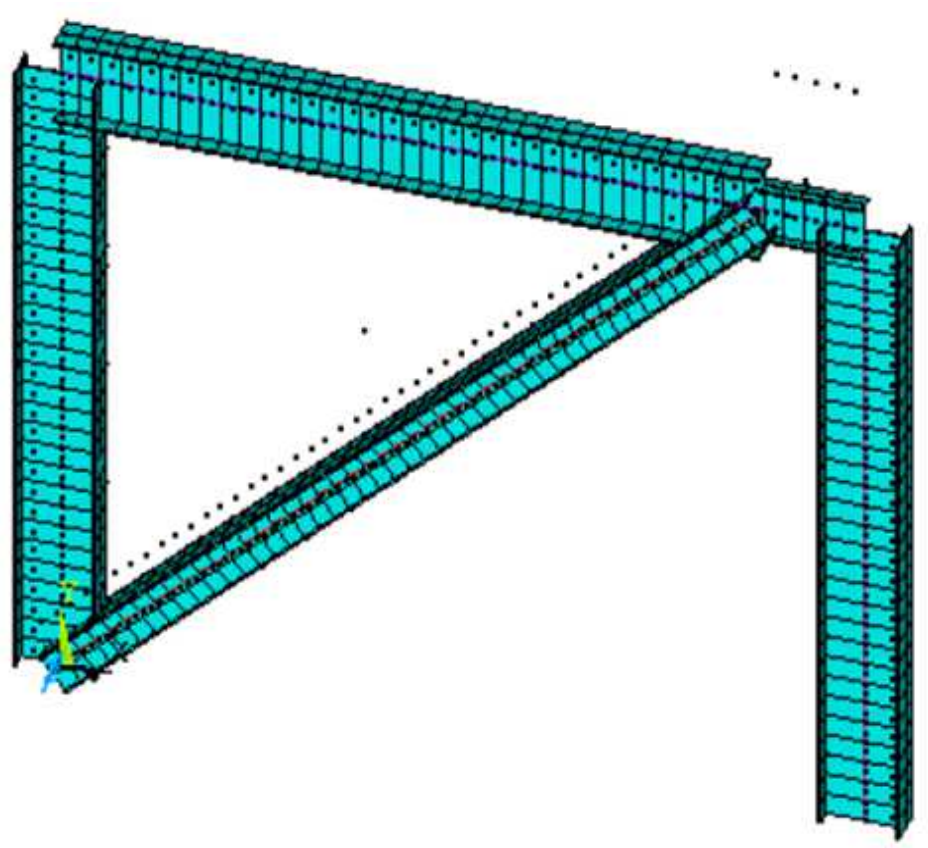

(a) 
Mazen Ali Musmar / American Journal of Engineering and Applied Sciences 6 (1): 31-41, 2013

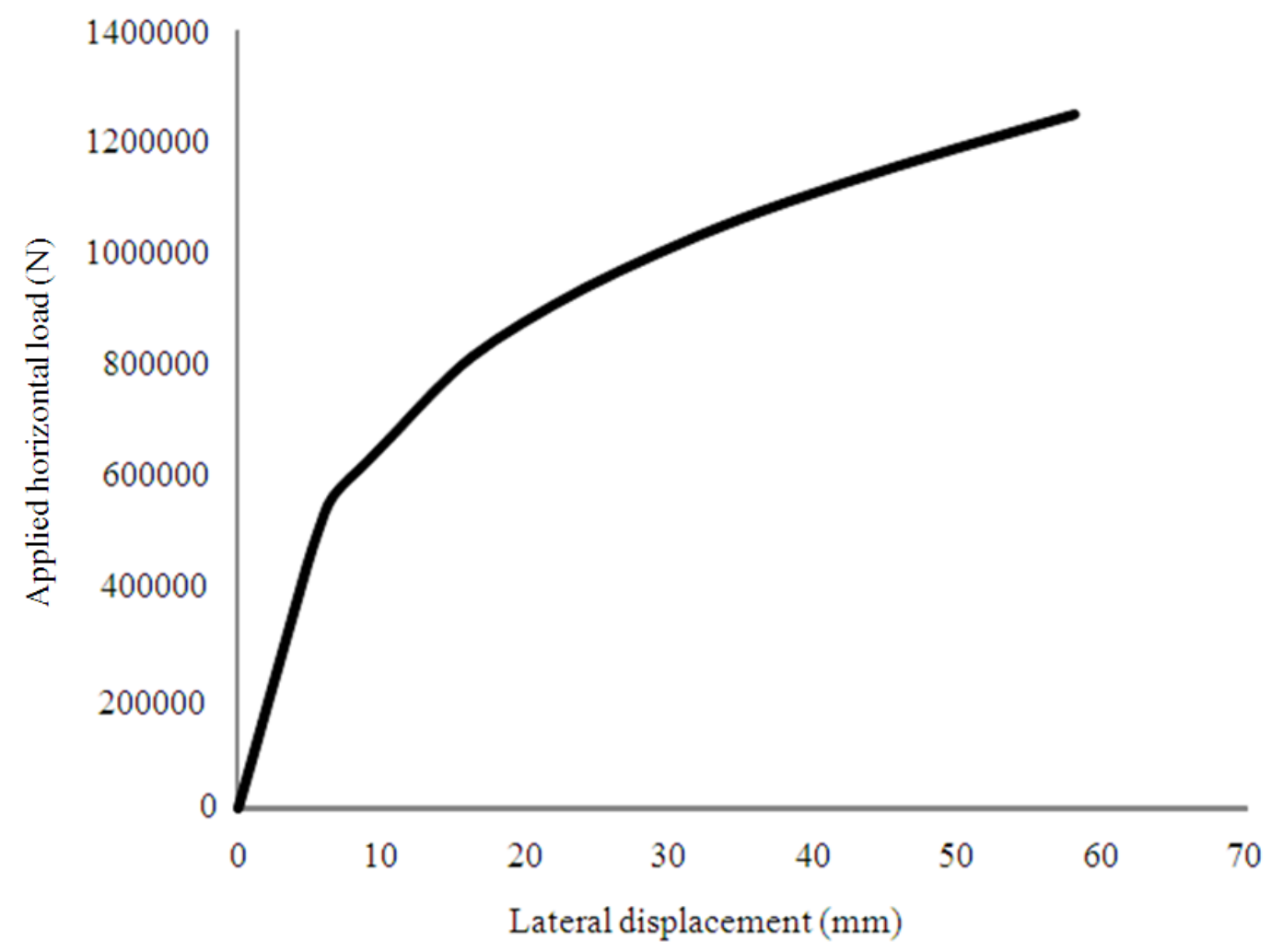

(b)

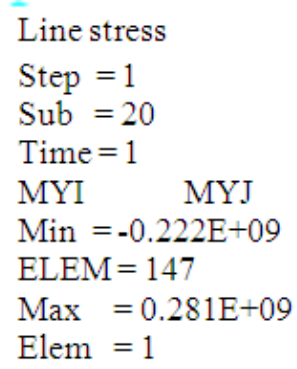

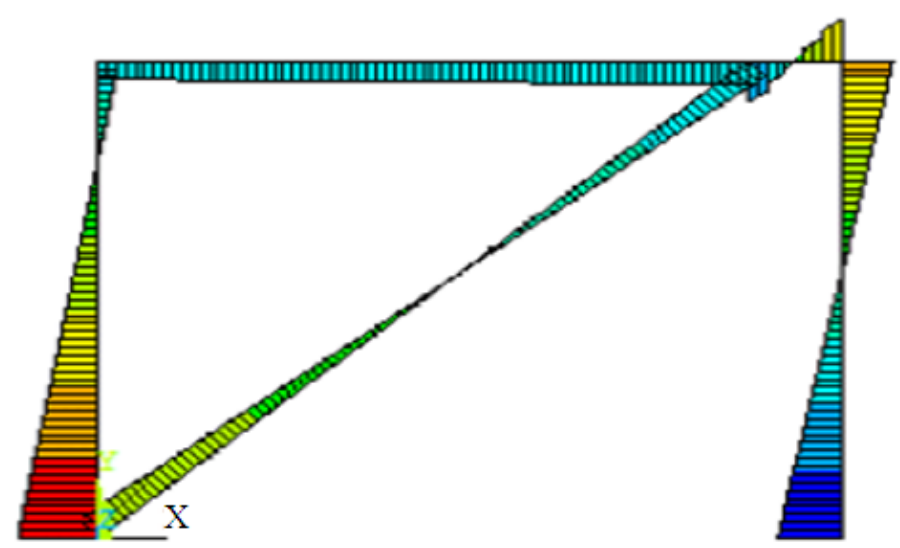

(c) 
Mazen Ali Musmar / American Journal of Engineering and Applied Sciences 6 (1): 31-41, 2013

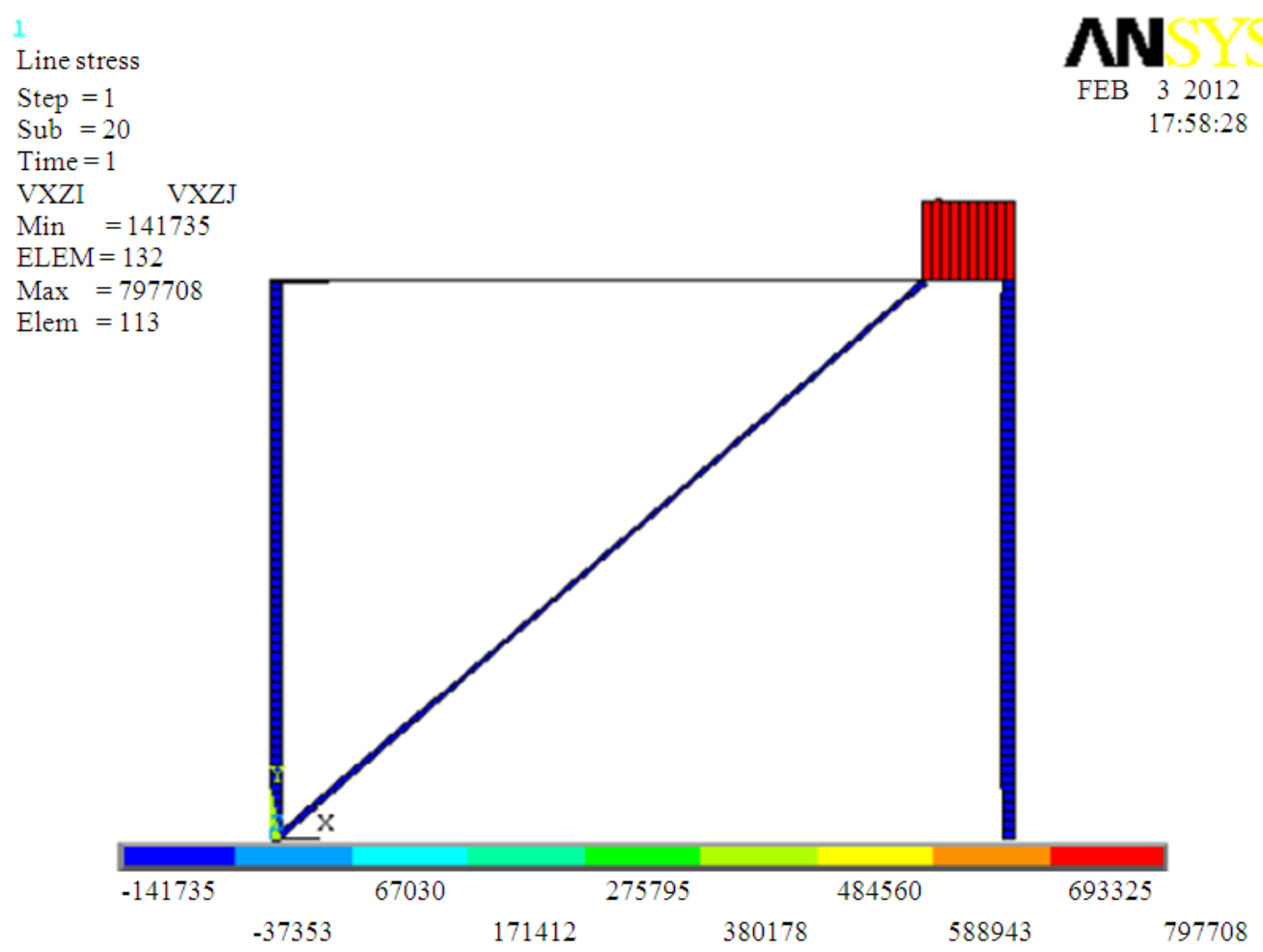

(d)

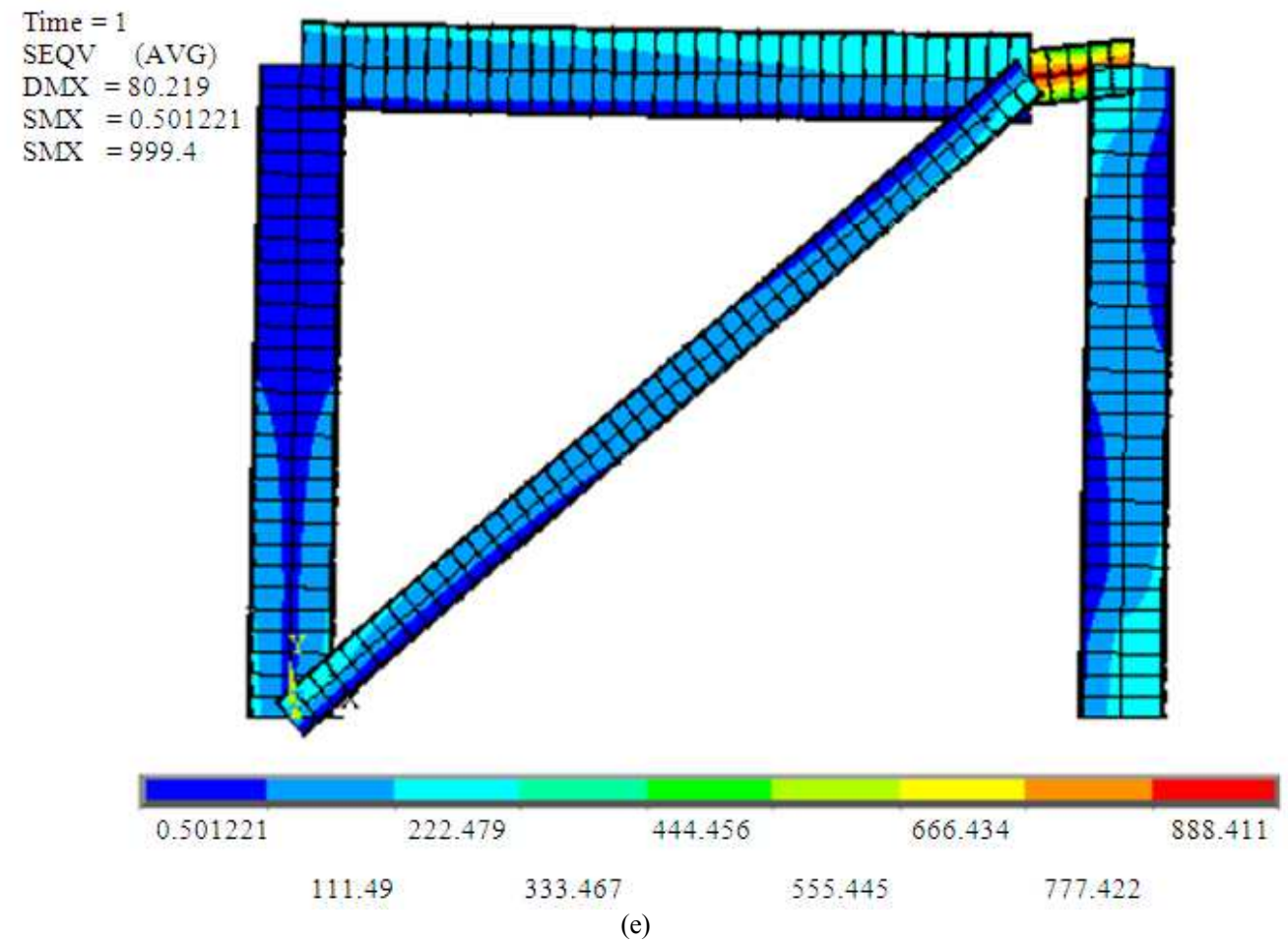




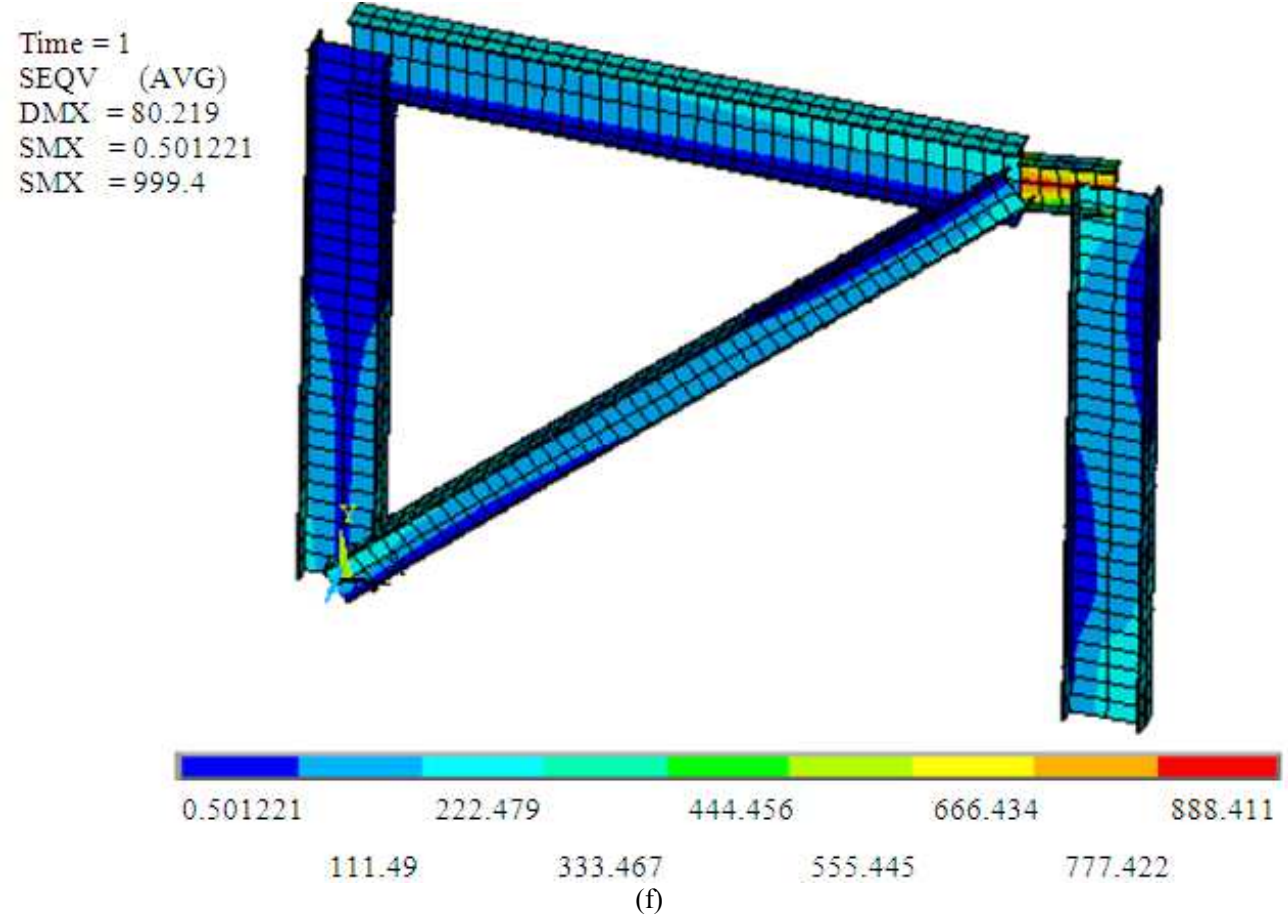

Fig. 6. (a) Isometric view of D-braced frame with reduced link section, (b) Load deflection curve, (c) Bending Moment diagram, (d) Shear Force diagram, (e) Von Mises stresses, (f) Von Mises stresses isometric view

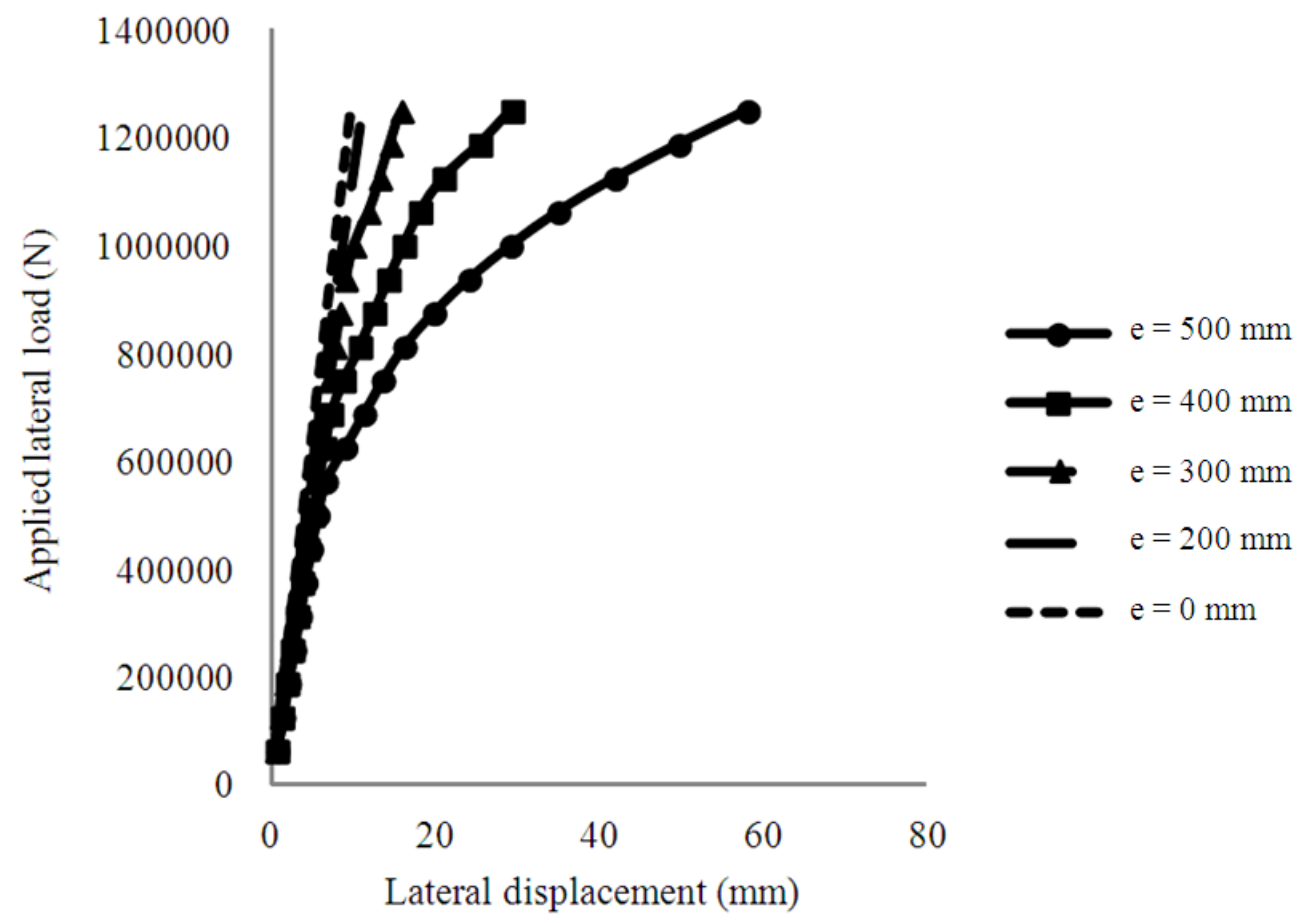

(a) 


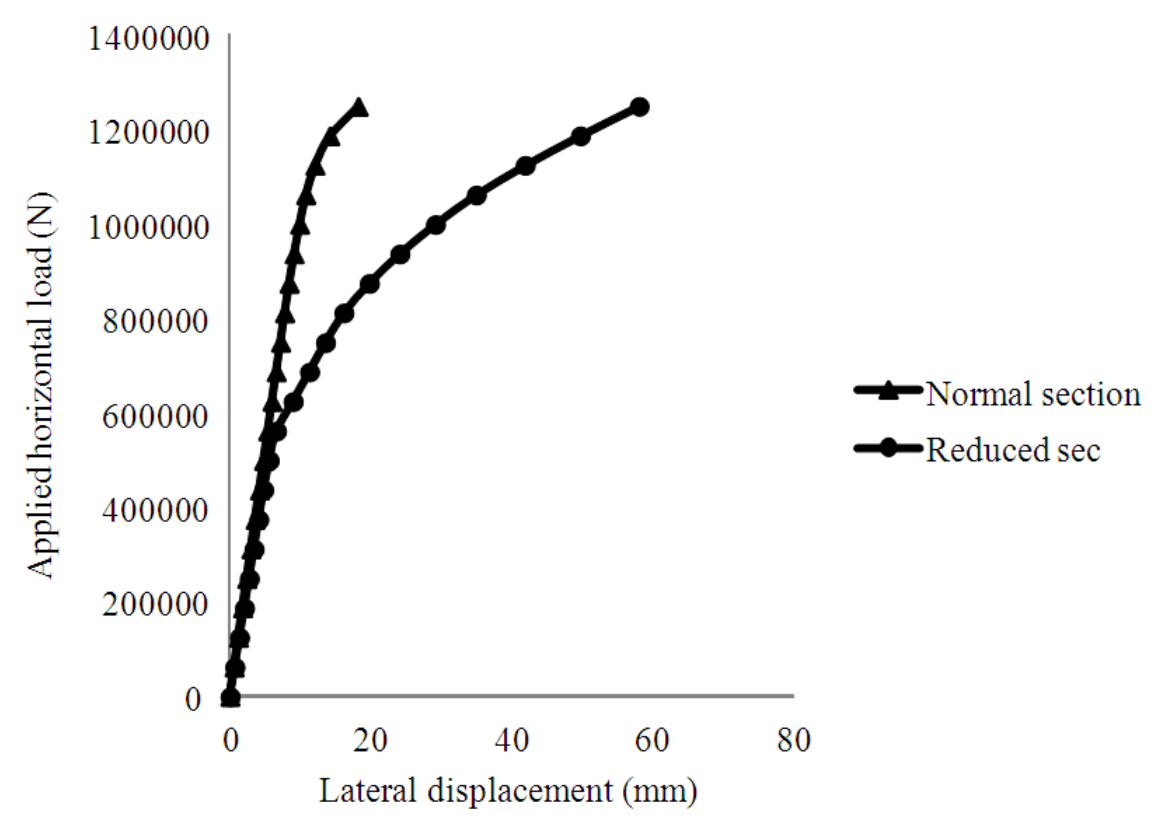

(b)

Fig. 7. (a) Effect of link length on lateral displacement for several link lengths (b) Effect of reduced link section on lateral displacement, link length $=500 \mathrm{~mm}$

Figure 7a illustrates the effect of link length on the frame lateral displacement in the case of reduced link section. Shear Link lengths of $200 \mathrm{~mm}, 300 \mathrm{~mm}, 400$ $\mathrm{mm}$ and $500 \mathrm{~mm}$ were used as well as concentric braced frame to compare the obtained results. It is noticed that the shorter the shear link is, the stiffer the frame becomes, resulting in remarkable reduction of energy dissipation.

Figure 7b shows that using a reduced link section enhances the ductility and consequently the energy dissipation appreciably.

\section{CONCLUSION}

The study concludes that the behavior of D-type eccentric frames is very much affected by the length and the section of the link.

In an eccentric D-braced frame, short shear links offer better stability and better energy dissipation than long flexural links, because the inelastic deformations occur along the whole link span in the case of shear links, while in flexural links inelastic deformations arise at the link ends.

The shear link is subjected to the highest internal shear forces and bending moments in comparison with the remaining members.
The shorter the shear link is, the stiffer the frame becomes, resulting in remarkable reduction of energy dissipation.

Using reduced link section enhances the D-braced frame ductility and its ability to dissipate energy, while possessing the necessary stiffness that would maintain the stability of the structure at severe loadings.

When links are properly designed, Eccentric Dbraced frames may offer high stiffness at working load level and large ductility at severe loadings.

\section{REFERENCES}

AISC, 2006. Steel construction manual, ANSI/AISC 341-05. American Institute of steel Construction, Chicago.

ANSYS, 1998. Structural analysis guide. Release, 6: 557-567.

Black, G.R., B.A. Wenger and E.P. Popov, 1980. Inelastic buckling of steel struts under cyclic load reversals. Earthquake Engineering Research Center, University of California, Berkely, CA.

Bruneau, M., C.M. Uang and A. Whittaker, 2011. Ductile Design of steel Structures. 2nd Edn., McGraw Hill, New York, ISBN-10: 9780071623957, pp: 905. 
Kasai, K. and E.P. Popov, 1986. General behavior of WF steel shear link beams. J. Struct. Eng, ASCE, 112: 362-382. DOI: 10.1061/(ASCE)07339445(1986)112:2(362)

Lee, K. and M. Bruneau, 2005. Energy dissipation demand of compression members in concentrically braced frames. Steel Comp. Struct., 5: 345-358.

Mitsumasa, M., Isao N., Mitsuru, S., 1996. Inelastic behavior of steel frames with steel beam seismic energy dissipation device. Proceedings of the 11th World Conference on Earthquake Engineering, (WCEE' 96).
Park, C.H., D.G. Lee and J.K. Kim, 1997. Effect of gravity load on seismic response of steel-framed structures. Eng. Struct., 19: 439-451. DOI: 10.1016/S0141-0296(96)00108-3

Roeder, C.W. and E.P. Popov, 1978. Eccentrically braced steel frames for Earthquakes. J. Struct. Div., ASCE, 104: 391-412. 